\title{
Влияние строения бокового азольного заместителя на экстракционные способности сополимеров на основе N-виниламидов
}

\author{
Кузнецов В.А., Быковский Д.В., Сорокин А.В., Лавлинская М.С. \\ ФГБОУ ВО «Воронежский государственный университет», Воронеж
}

Поступила в редакцию 11.09.2017 г.

\begin{abstract}
Радикальной полимеризацией получены сополимеры $N$-винилкапролактама и $N$ винилформамида с $N$-винилимидазолом, 1-винил-3,5-диметилпиразолом и 1-метакрилоил-3,5диметилпиразолом. Определена их способность к растворению в воде. Для водорастворимых сополимеров изучена эксракционная способность по отношению к $\alpha$-аминокислоте гистидину. Установлено, что лучшие количественные характеристики экстракционного процесса достигаются при использовании сополимеров, содержащих в макроцепи имидазольные боковые заместители. Найдено, что эффективность процесса извлечения также зависит от конформационного состояния макромолекулы в растворе.
\end{abstract}

Ключевые слова: сополимеры, $N$-виниламиды, $N$-винилазолы, экстракция, гистидин

\section{The effect of the side azole substitutes on extraction ability of the copolymers based on $\mathrm{N}$-vinylamides}

\author{
Kuznetsov V.A., Bykovskii D.V., Sorokin A.V., Lavlinskaya M.S. \\ Voronezh State University, Voronezh
}

\begin{abstract}
The aim of this work is investigation of the influence of the nature of the side azole substitutes on the extraction ability of $N$-vinylcaprolactam (VC) $/ N$-vinylformamide (VF) with $N$-vinylimadazole (VI), 1 vinyl-3,5-dimethylpyrazole (VDMP) and 1-methacryloyl-3,5-dimethylpyrazole (MDMP) copolymers in relation to essential $\alpha$-amino acid histidine. The copolymers with different monomer content were synthesized by free radical copolymerization in dioxane solution with AIBN as inintiator. It was found that VC-VI and VFVI copolymers are water soluble at all monomer content, and water solubility of the other polymers depends on VDMP and MDMP containing in the macro chain. VC-VDMP copolymers are water soluble below 0.25 mol frac VDMP containing, and VC-MDMP - below 0.05 mol frac MDMP containing. For VF-VDMP and VF-MDMP - below 0.25 and $0.07 \mathrm{~mol}$ frac VDMP and MDMP containing respectively. All water soluble copolymers were used in two-phase water-salt extraction system with the using of ammonium sulphate as salting-out agent for histidine removing. It's shown that the most efficient extragents are copolymers containing imidazole cycles as side substitutes due to its higher base property of the «pyridine» nitrogen atom compared to a pyrazole cycle. It's established for VC-VI and VF-VI copolymers that extraction efficiency depends on content and size of the coils of the macromolecules in aqueous solutions. The degree of extraction $R$ correlates with hydrodynamic radii $R_{h}$ of the macromolecules. With increasing of the $R_{h}$ values degree of extraction also increases. To sum up the extration ability of the copolymers containing different azole side substitutions in relation to histidine is researched.
\end{abstract}

Keywords: copolymers, $N$-vinylamides, $N$-vinylazoles, extraction, histidine.

\section{Введение}

Водорастворимые полимеры класса поли- $N$-виниламидов находят все новые применения в различных областях человеческой деятельности. Высокий интерес к 
этим материалам как с практической, так и исследовательской точки зрения обусловлен наличием у них широкого спектра ценных свойств, особо среди которых стоит подчеркнуть низкую токсичность, биосовместимость и высокую комплексообразующую способность. Успешно такие полимеры зарекомендовали себя и как экстрагенты для широкого класса биологически активных веществ (БАВ), таких как незаменимые $\alpha$-аминокислоты [1,2], водо- и жирорастворимые витамины [3], иммунодепрессанты [4], ванилины [5], таннины и кофеин [6] и др. Стоит отметить, что водно-солевые экстракционные системы на основе поли- $N$-виниламидов выгодно отличаются от классических систем «органический растворитель-вода» более высокими степенями извлечения при однократном экстрагировании и безопасностью для человека и окружающей среды. Более того, наличие термочувствительных свойств в физиологическом диапазоне температур $\left(32-37^{\circ} \mathrm{C}\right)$ у некоторых представителей ряда поли- $N$-виниламидов, например, поли- $N$-винилкапролактама [7-8], позволяет осуществлять бессолевую экстракцию [9], а также реэкстракцию - выделение целевого экстрагируемого вещества из комплекса полимер-БАВ [10] - под температурным воздействием без дополнительных реагентов.

Хорошо известно, что сочетание в макроцепи звеньев с различными боковыми заместителями позволяет значительно расширить спектр возможного применения образующегося полимера. В связи с чем для регулирования экстракционных свойств полимеров на основе $N$-виниламидов возможно проведение сополимеризации последних с мономерами, боковые заместители которых характеризуются высокой комплексообразующей способностью. Особый интерес в качестве сомономеров представляют винильные производные азолов различного строения. Неравномерное распределение электронной плотности в азольных циклах и наличие «пиридинового» атома обуславливают способность к взаимодействию с широким спектром неорганических и органических соединений. Эта способность зависит от строения гетероциклического заместителя. В связи с этим представляет интерес изучение влияния строения азольного бокового заместителя в макроцепи сополимера типа «Nвиниламид - $N$-винилазол» на экстракционные способности последнего.

Цель данной работы - изучение влияния строения бокового азольного заместителя на экстракционную способность сополимеров $N$-винилкапролактама и $N$ винилформамида по отношению к незаменимой $\alpha$-аминокислоте гистидину в условиях жидкостной экстракции.

\section{Эксперимент}

В работе использованы товарные мономеры $N$-винилкапролактам (ВК), $N$ винилформамид (ВФ) и $N$-винилимидазол (ВИ) (все Acros Organic, США), которые очищались согласно известным методикам непосредственно перед использованием.<smiles>C=CN1CCCCCC1=O</smiles>

$\mathrm{BK}$<smiles>C=CNC=O</smiles>

$\mathrm{B} \Phi$<smiles>C=Cn1nc(C)cc1C</smiles>

ВДМП<smiles>C=C(C)C(=O)n1nc(C)cc1C</smiles>

МДМП<smiles>C=Cn1ccnc1</smiles>

ВИ<smiles>NC(Cc1c[nH]cn1)C(=O)O</smiles>

Гистидин

Пиразолсодержащие мономеры 1-винил-3,5-диметилпиразол (ВДМП) и 1метакрилоил-3,5-диметилпиразол (МДМП) синтезировали согласно [11].

Синтез сополимеров ВК-ВИ, ВК-ВДМП, ВК-МДМП, ВФ-ВИ, ВФ-ВДМП, ВФ-МДМП осуществляли в растворе диоксана с суммарной концентрацией мономеров $\left[\mathrm{M}_{1}\right]+\left[\mathrm{M}_{2}\right]=1.0$ моль/дм ${ }^{3}$, изменяющихся в интервале 0.1-0.9 мол. дол., в условиях 
термоиницирования в присутствии инициатора азо-бис-изомасляной кислоты с концентрацией $1 \cdot 10^{-2}$ моль/дм³ ${ }^{3}$ Раствор мономеров вносили в заранее подготовленные ампулы, которые дегазировали в вакууме, после чего их запаивали. Реакцию проводили в течение 6 часов при температуре $65 \pm 2^{\circ} \mathrm{C}$. Полученные сополимеры выделяли осаждением в петролейном эфире, после чего сушили в вакуумном сушильном шкафу при $55 \pm 2{ }^{\circ} \mathrm{C}$ до постоянной массы.

Составы полученных сополимеров определяли методами УФ- и ИКспектроскопии. В УФ-спектрах водных растворов, полученных на спектрофотометре Shimadzu UV 1800, учитывались заранее определенные максимумы светопоглощения водных растворов сополимеров при 192 нм для звеньев ВК и ВФ, при 311 нм для звеньев с азольными циклами.

ИК-спектры получены на приборе Bruker Vertex 70 с Фурье-преобразователем методом нарушенного полного внутреннего отражения в диапазоне частот 400-4000 $\mathrm{cm}^{-1}$. При определении составов сополимеров учитывалось соотношение площадей под полосами поглощения при $1635 \mathrm{~cm}^{-1}$ для звеньев ВК, $1643 \mathrm{~cm}^{-1}$ для звеньев ВФ и при $1550 \mathrm{~cm}^{-1}$ для звеньев, содержащих азольные циклы [12].

Характеристическую вязкость сополимеров [ $\eta$ рассчитывали из экспериментальных данных, полученных в вискозиметре Уббелоде в хлороформе ил $0.2 \mathrm{~N}$ водном растворе $\mathrm{NaCl}$ при $20{ }^{\circ} \mathrm{C}$, рассчитывали общепринятым методом. Водный раствор хлорида натрия был выбран в качестве растворителя для сополимеров на основе ВФ для подавления влияния полиэлектролитного эффекта, затрудняющего определение величины [ๆ].

Размеры частиц сополимеров в водных растворах определяли методом динамического светорассеяния в стеклянных кюветах на модульном спектрометре статического и динамического светорассеяния «Photocor Complex», оборудованным $\mathrm{He}-\mathrm{Ne}$ лазером с длинной волны $\lambda=632.8$ нм. Результаты обрабатывали с помощью программного пакета «DynaLS».

Жидкостную экстракцию гистидина $\left(c_{0}=2.4 \cdot 10^{-4}\right.$ моль/дм $\left.{ }^{3}\right)$ проводили в присутствии высаливателя сульфата аммония, концентрация сополимера составляла

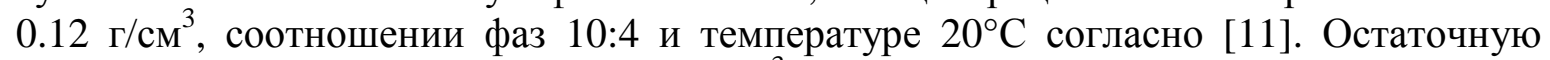
концентрацию $\alpha$-аминокислоты, моль/дм ${ }^{3}$, определяли спектрофотометрически по заранее определенному максимуму светопоглощения $\lambda_{\max }=211$ нм с помощью градуировочного графика. Степени извлечения $R$ и коэффициенты распределения $D$ рассчитывали по известным формулам в соответствие с [11].

\section{Обсуждение результатов}

Радикальной сополимеризацией в присутствии инициатора азодиизобутиронитрила в растворе диоксана получены сополимеры $\mathrm{N}$-винилкапролактама с $\mathrm{N}$ винилимидазолом, 1-винил-3,5-диметилпиразолом, 1-метакрилоил-3,5-диметилпиразолом; а так же аналогичные сополимеры для N-винилформамида. Как и следовало ожидать, полимеризация протекает за счет раскрытия двойной связи $C=C$ винильных групп, о чем свидетельствует отсутствие характеристической полосы поглощения $v_{\mathrm{C}=\mathrm{C}}$ в ИК-спектрах синтезированных продуктов. Составы полученных сополимеров определяли методами УФ- и ИК-спектроскопии. Результаты определения представлены в таблице 1 .

Сополимеры ВК-ВИ и ВФ-ВИ являются водорастворимыми во всех областях составов, т.к. гомополимеры, соответствующие этим мономерам также водорастворимы. Водорастворимость сополимеров, содержащих в макроцепи пиразолсодержащие звенья, сильно зависит от содержания последних. С увеличением их количества 
значительно повышается гидрофобность макромолекул, что приводит к потере способности к растворению в воде сополимеров. Водорастворимыми являются только сополимеры ВК, содержащие не более 0.25 мол. дол. звеньев ВДМП или 0.05 мол. дол. звеньев МДМП; для ВФ - не более 0.25 мол.дол. ВДМП и 0.07 мол.дол. МДМП.

Таблица 1. Характеристика синтезированных сополимеров

\begin{tabular}{|c|c|c|c|c|c|}
\hline \multirow{2}{*}{ № п/п } & \multirow{2}{*}{$\begin{array}{c}\text { Содержание ВК (ВФ) } \\
\text { в мономерной смеси, } \\
\text { мол. дол. }\end{array}$} & \multicolumn{2}{|c|}{$\begin{array}{c}\text { ВК (ВФ) в сополимере, } \\
\text { мол. дол.: }\end{array}$} & \multirow{2}{*}{$\begin{array}{c}{[\eta], \text { дл/г, }} \\
\text { этанол } \\
(0.2 \mathrm{~N} \mathrm{NaCl}), \\
20{ }^{\circ} \mathrm{C} \\
\end{array}$} & \multirow{2}{*}{$\begin{array}{l}R_{h}, \text { нм, } \\
\text { этанол }\end{array}$} \\
\hline & & УФ & ИК & & \\
\hline \multicolumn{6}{|c|}{ ВК-ВДМП } \\
\hline 1 & 0.10 & 0.17 & 0.13 & 0.09 & 73 \\
\hline 2 & 0.30 & 0.41 & 0.39 & 0.13 & 108 \\
\hline 3 & 0.50 & 0.46 & 0.49 & 0.21 & 120 \\
\hline 4 & 0.70 & 0.63 & 0.75 & 0.30 & 137 \\
\hline 5 & 0.90 & 0.89 & 0.93 & 0.38 & 159 \\
\hline \multicolumn{6}{|c|}{ ВК-МДМП } \\
\hline 6 & 0.10 & 0.12 & 0.15 & 0.13 & 85 \\
\hline 7 & 0.30 & 0.51 & 0.59 & 0.22 & 151 \\
\hline 8 & 0.50 & 0.79 & 0.82 & 0.34 & 196 \\
\hline 9 & 0.70 & 0.94 & 0.93 & 0.38 & 217 \\
\hline 10 & 0.90 & 0.98 & 0.99 & 0.49 & 256 \\
\hline \multicolumn{6}{|c|}{ ВК-ВИ } \\
\hline 11 & 0.10 & 0.22 & 0.24 & 0.51 & 261 \\
\hline 12 & 0.30 & 0.43 & 0.41 & 0.42 & 224 \\
\hline 13 & 0.50 & 0.55 & 0.53 & 0.33 & 196 \\
\hline 14 & 0.70 & 0.76 & 0.73 & 0.29 & 171 \\
\hline 15 & 0.90 & 0.87 & 0.88 & 0.19 & 157 \\
\hline \multicolumn{6}{|c|}{ ВФ-ВДМП } \\
\hline 16 & 0.10 & 0.19 & 0.17 & 0.12 & 76 \\
\hline 17 & 0.30 & 0.45 & 0.41 & 0.25 & 116 \\
\hline 18 & 0.50 & 0.54 & 0.57 & 0.34 & 125 \\
\hline 19 & 0.70 & 0.65 & 0.68 & 0.40 & 144 \\
\hline 20 & 0.90 & 0.89 & 0.93 & 0.49 & 171 \\
\hline \multicolumn{6}{|c|}{ ВФ-МДМП } \\
\hline 21 & 0.10 & 0.12 & 0.15 & 0.18 & 90 \\
\hline 22 & 0.30 & 0.52 & 0.55 & 0.32 & 159 \\
\hline 23 & 0.50 & 0.80 & 0.81 & 0.46 & 208 \\
\hline 24 & 0.70 & 0.95 & 0.91 & 0.49 & 232 \\
\hline 25 & 0.90 & 0.97 & 0.99 & 0.56 & 273 \\
\hline \multicolumn{6}{|c|}{ ВФ-ВИ } \\
\hline 26 & 0.10 & 0.11 & 0.13 & 0.52 & 269 \\
\hline 27 & 0.30 & 0.36 & 0.39 & 0.43 & 204 \\
\hline 28 & 0.50 & 0.49 & 0.44 & 0.32 & 159 \\
\hline 29 & 0.70 & 0.66 & 0.69 & 0.23 & 136 \\
\hline 30 & 0.90 & 0.89 & 0.93 & 0.17 & 104 \\
\hline
\end{tabular}

Определение молекулярных масс синтезированных полимеров методом гельпроникающей хроматографии чрезвычайно затруднено в виду сильных взаимодействий между анализируемыми макромолекулами и сорбентом колонки. Поэтому для косвенной характеристики величин молекулярных масс полученных продуктов нами были рассчитаны величины характеристической вязкости [ๆ] (табл. 1). Установлено, 
что с увеличением содержания звеньев ВК и ВФ в сополимерах с пиразолсодержащими звеньями, величина характеристической вязкости возрастает. Для сополимеров ВК-ВИ и ВФ-ВИ величина [ๆ] увеличивается с содержанием звеньев ВИ. Подобное поведение может быть объяснено различным сольватирующим эффектом растворителя по отношению к разного рода звеньям. Это предположение косвенно подтверждается данными о размерах гидродинамических радиусов $R_{h}$, определенных методом динамического светорассеяния (табл. 1).

Изучение экстрагирующей способности синтезированных полимеров проводилось только водорастворимыми сополимерами в условиях жидкостной экстракции в присутствии легкорастворимого высаливателя сульфата аммония, обеспечивающего наиболее полное выделение полимера в отдельную фазу. Основываясь на ранее проведенных исследованиях $[1,2,9]$, было выбрано соотношение водной к органической фазе 10:4, позволяющее достигнуть максимальных величин $R$ и $D$ при экстракции $\alpha$-аминокислот.

Количественные характеристики экстракционного процесса представлены в таблице 2. Как видно из данных, синтезированные полимеры являются эффективными экстрагентами для гистидина, обеспечивая практически полное его извлечение при однократном экстрагировании. В литературе имеются данные о величинах степени извлечения и коэффициента распределения при жидкостной экстракции гистидина гомополимерами поли- $N$-винилкапролактама и поли- $N$-винилформамида [11, 9]. Очевидно, что значения $R$ и $D$ для сополимеров выше, чем для гомополимеров, что объясняется наличием в макроцепи функциональных групп других типов, так же вступающих во взаимодействие с $\alpha$-аминокислотой.

Таблица 2. Количественные характеристики жидкостной экстракции гистидина $\left(\mathrm{pH}=4.2 \pm 0.2 ; \mathrm{T}=20^{\circ} \mathrm{C} ; n=3 ; P=0.95\right)$

\begin{tabular}{|c|c|c|c|c|}
\hline $\begin{array}{l}\text { № } \\
\Pi / \Pi\end{array}$ & $\begin{array}{c}\text { ВК (ВФ) в мономерной сме- } \\
\text { си, мол. дол. }\end{array}$ & [ๆ], дл/Г & $R, \%$ & $D$ \\
\hline 1 & 2 & 3 & 4 & 5 \\
\hline \multicolumn{5}{|c|}{ ВК-ВФ } \\
\hline 1 & 0.22 & 0.50 & 90.2 & $91 \pm 4$ \\
\hline 2 & 0.43 & 0.49 & 93.1 & $127 \pm 6$ \\
\hline 3 & 0.55 & 0.33 & 95.3 & $167 \pm 3$ \\
\hline 4 & 0.76 & 0.24 & 96.3 & $122 \pm 2$ \\
\hline 5 & 0.87 & 0.15 & 94.9 & $90 \pm 4$ \\
\hline \multicolumn{5}{|c|}{ ВК-ВИ } \\
\hline 6 & 0.22 & 0.51 & 99.1 & $117 \pm 6$ \\
\hline 7 & 0.43 & 0.42 & 97.3 & $113 \pm 5$ \\
\hline 8 & 0.55 & 0.33 & 95.8 & $95 \pm 3$ \\
\hline 9 & 0.76 & 0.29 & 94.0 & $78 \pm 4$ \\
\hline 10 & 0.87 & 0.19 & 93.6 & $66 \pm 2$ \\
\hline \multicolumn{5}{|c|}{ ВФ-ВИ } \\
\hline 11 & 0.11 & 0.52 & 98.4 & $110 \pm 3$ \\
\hline 12 & 0.36 & 0.43 & 97.3 & $108 \pm 4$ \\
\hline 13 & 0.49 & 0.32 & 96.3 & $107 \pm 5$ \\
\hline 14 & 0.66 & 0.23 & 95.1 & $106 \pm 3$ \\
\hline 15 & 0.89 & 0.17 & 84.2 & $105 \pm 2$ \\
\hline \multicolumn{5}{|c|}{ ВК-ВДМП } \\
\hline 16 & 0.92 & 0.36 & $99 \pm 3$ & 95 \\
\hline 17 & 0.93 & 0.38 & $99 \pm 2$ & 96 \\
\hline
\end{tabular}




\begin{tabular}{|c|c|c|c|c|}
\hline \multicolumn{5}{|c|}{ ВК-МДМП } \\
\hline 1 & 2 & 3 & 4 & 5 \\
\hline 18 & 0.96 & 0.41 & $98 \pm 4$ & 90 \\
\hline 19 & 0.98 & 0.49 & $98 \pm 1$ & 91 \\
\hline \multicolumn{5}{|c|}{ ВФ-ВДМП } \\
\hline 20 & 0.75 & 0.46 & $95 \pm 6$ & 93 \\
\hline 21 & 0.93 & 0.49 & $98 \pm 4$ & 95 \\
\hline \multicolumn{5}{|c|}{ ВФ-МДМП } \\
\hline 22 & 0.93 & 0.51 & $88 \pm 2$ & 84 \\
\hline 23 & 0.99 & 0.56 & $91 \pm 5$ & 89 \\
\hline \multicolumn{5}{|c|}{ ПВФ } \\
\hline 16 & 1.00 & 0.34 & 83.3 & $41 \pm 2$ \\
\hline \multicolumn{7}{|l|}{} & 1.00 & 0.37 & 84.5 & $82 \pm 3$ \\
\hline 17 & 1.00 & 0.42 & 88.2 & $86 \pm 4$ \\
\hline 18 & \multicolumn{5}{|l|}{} \\
\hline
\end{tabular}

Как видно из полученных данных, экстракционная способность сополимеров, содержащих в составе имидазольные циклы, выше, чем для сополимеров, в состав которых входят пиразольные фрагменты. Причиной этого является более высокая основность «пиридинового» атома азота, входящего в состав имидазального цикла [13]. В свою очередь, сополимеры, содержащие звенья ВДМП, более эффективны как экстрагенты, по сравнению с сополимерами со звеньями МДМП. Причиной этого является сопряжение, возникающее между неподеленной электронной парой атома азота и атомом кислорода, входящего в состав карбонильной группы метакрилоилового фрагмента.

На экстракционную эффективность влияет не только состав и строение макромолекул сополимеров, но и их конформационное состояние в растворе. На рис. 1 представлены графики зависимости степени извлечения $R$ и гидродинамического радиуса $R_{h}$ макромолекул сополимеров ВК-ВИ и ВФ-ВИ от их состава.

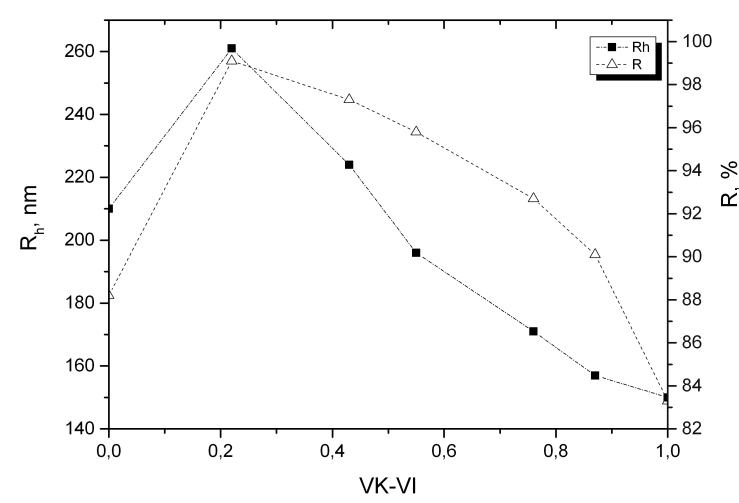

a

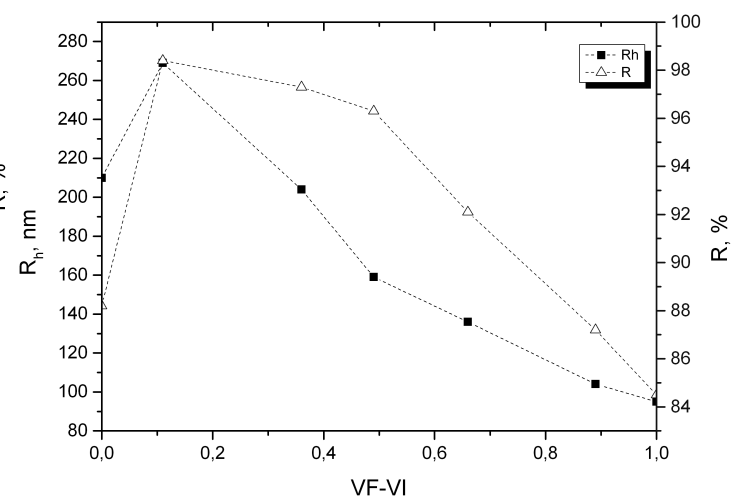

б

Рис. 1. Зависимости степени извлечения и гидродинамического радиуса от состава сополимера: а-ВК-ВИ; б-ВФ-ВИ.

Как видно из рисунка 1 , обе зависимости имееют нелинейный вид и содержат ярко выраженные экстремумы. Наибольший размер полимерного клубка в случае сополимера ВК-ВИ соответствует образцу, содержащему 0.22 мол. дол. ВК, для сополимера ВФ-ВИ - 0.11 мол. дол. ВФ. Это связано, по-видимому, с различной степенью гидратированности амидных и имидазольных заместителей макромолекул. Кроме того, наблюдается корреляция между характером изменения $R$ и $R_{h}$ от состава 
сополимера: более развернутой конформации соответствует большее значение $R$. Это связано с тем, что большему значению $R_{h}$ соответствует более развернутая конформация макромолекул, приводящая к увеличению доступности центров макромолекул, способных к взаимодействию с аминокислотой.

\section{Заключение}

Радикальной полимеризацией получены сополимеры $N$-винилкапролактама и $N$-винилформамида с 1-винил-3,5-диметилпиразолом, 1-метакрилоил-3,5диметилпиразолом и $N$-винилимидазолом. Исследование их экстракционной способности по отношению к гистидину показало, что наиболее полное извлечение достигается в случае применения сополимеров, содержащие азольные циклы. Также установлена корреляция между величиной гидродинамического радиуса макромолекулы и степенью извлечения $\alpha$-аминокислоты.

\section{Список литературы}

1. Шкинев В.М., Мокшина Н.Я., Хохлов В.Ю., Спиваков Б.Я. // Докл. акад. наук. 2013. T. 448. С. 427-430.

2. Мокшина Н.Я., Быковский Д.В., Шаталов Г.В., Пахомова О.А. // Журн. аналит. химии. 2016. Т. 71. № 2. С. 208-211.

3. Коренман Я.И., Мокшина Н.Я, Зыков А. В., Быковский Д.В. и др. // Журн. физич. химии. 2011. Т. 85. № 11. С. 2142-2146.

4. Коренман Я.И., Логинова О.А., Мокшина Н.Я., Шаталов Г.В. и др. // Конденсированные среды и межфазные гранииы. 2014. Т. 16. № 3. С. 347-353.

5. Мокшина Н.Я., Пахомова О.А., Шаталов Г.В., Лавлинская М.С. // Изв. вузов. Химия и хим. технол. 2017. Т. 60. Вып. 8. С. 13-19.

6. Суханов П.Т., Ильин А.Н., Чурилина Е.В., Шаталов Г.В. // Аналитика и контроль. 2015. T. 19. № 3. C. 268-273.

7. Kuznetsov V.A., Kushchev P.O., Blagodatskikh I.V. et al. // Colloid Polym Sci. 2016. Vol. 294. pp. 889-899.

\section{References}

1. Shkinev V. M., Mokshina N.Ya., Khokhlov V.Yu., and Spivakov B.Ya., Doklady Chemistry, 2013, Vol. 448, Part 2, pp. 49-51

2. Mokshina N.Ya., Bykovskii D.V., Shatalov G.V., Pakhomova O.A., J Analyt Chem., 2016, Vol. 71, No 2. pp. 201-204. DOI: 10.1134/S1061934816020106.
8. Кирш Ю.Э. Поли- $N$-винилпирролидон и другие поли-N-виниламиды. М. Наука. 1998. $252 \mathrm{c}$.

9. Быковский Д.В., Мокшина Н.Я., Пояркова Т.Н., Шаталов Г.В. и др. // Изв. вузов. Химия и хим. технол. 2014. Т. 57. № 7. C. 73-77.

10. Лавлинская М.С., Шаталов Г.В., Пахомова О.А., Мокшина Н.Я. и др. // Изв. вузов. Химия и хим. технол. 2016. Т. 59. № 7. C. $55-60$.

11. Шаталов Г.В., Лавлинская М.С., Мокшина Н.Я., Пахомова О.А. и др. // Журн. прикладной химии. 2016. Т. 89. № 1. С. 112118.

12. Беллами Л. Инфракрасные спектры сложных молекул / Пер. с англ. под ред. Ю.А. Пентина. М. 1963. 592 с.

13. Нейланд О.Я. Органическая химия. М. Высшая школа. 1990. 751 с.

3. Korenman Ya.I., Mokshina N.Ya., Zykov A.V., Bykovskii D.V. et al., Rus J Phys Chem. A, 2011, Vol. 85, No 11, pp. 2000-2004.

4. Korenman Ya.I., Loginova O.A., Mokshina N.Ya., Shatalov G.V. et al. // Kondensirovannye sredy i mezhfaznye granicy (Condensed matter and interphases). 2014. Vol. 19. No 3. pp. 347353. 
5. Mokshina N.Ya., Pakhomova O.A., Shatalov G.V., Izv Vyssh Uchebn Zaved. Khim Khim Tekhol,. 2017, Vol. 60, No 8, pp. 13-19. DOI:10.6060/tcct.2017608.5577

6. Sukhanov P.T., Il'yin A.N., Churilina E.V., Shatalov G.V., Analitika i kontrol', 2015, Vol. 19, No 3, pp. 268-273. DOI:10.15826/analitika.2015.19.3.005

7. Kuznetsov V.A., Kushchev P.O., Blagodatskikh I.V. et al., Colloid Polym Sci., 2016, Vol. 294, pp. 889-899. DOI:10.1007/s00396016-3843-5

8. Kirsh Yu.E. Water Soluble Poly-NVinylamides: Synthesis and Physicochemical Properties. London: Methuen \& Co. Ltd, New York: John Wiley \& Sons, Inc., 1998, 240 p. 9. Bykovskii D.V., Mokshina N.Ya., Poyarkova T.N., Shatalov G.V. et al., Izv Vyssh Uchebn

Кузнецов Вячеслав Алексеевич - д.х.н., доцент, профессор кафедры высокомолекулярных соединений и коллоидной химии Воронежского государственного университета, Воронеж

Быковский Дмитрий Владимирович аспирант кафедры высокомолекулярных соединений и коллоидной химии Воронежского государственного университета, Воронеж

Сорокин Андрей Викторовия - магистрант 1 года обучения кафедры высокомолекулярных соединений и коллоидной химии Воронежского государственного университета, Воронеж

Лавлинская Мария Сергеевна - к.х.н., инженер кафедры высокомолекулярных соединений и коллоидной химии Воронежского государственного университета, Воронеж
Zaved. Khim Khim Tekhnol., 2014, Vol. 57, No 7, pp. 73-77.

10.Lavlinskaya M.S., Shatalov G.V., Pakhomova O.A., Mokshina N.Ya., Izv Vyssh Uchebn Zaved. Khim Khim Tekhnol., 2016, Vol. 59, No 7, pp. 55-60.

11.Shatalov G.V., Lavlinskaya M.S., Mokshina N.Ya., Pakhomova O.A. et al., Rus J App Chem. 2016, Vol. 89, No 1, pp. 140-146. DOI: 10.1134/S1070427216010225

12.Bellamy L.J. The infra-red spectra of complex molecules. London: Methuen \& Co. Ltd, New York: John Wiley \& Sons, Inc., 1962, 592 p.

13.Neyland O. Ya. Organic chemistry. M., Vyshaya shkola, 1990, $751 \mathrm{p}$.

Kuznetsov Vyacheslav A. - Dr. Sci. (Chem.), professor of chair of macromolecules compounds and colloid chemistry of Voronezh State University, Voronezh; -mail: dr.v.kuznetsov@ gmail.com

Bykovskii Dmitrii V. - post-graduate student of chair of macromolecules compounds and colloid chemistry of Voronezh State University, Voronezh; e-mail: nasredinne@mail.ru

Sorokin Andrey V. - master student of the first year education of chair of macromolecules compounds and colloid chemistry of Voronezh State University, Voronezh, e-mail: pzkmph2@gmail.com

Lavlinskaya Maria S. - PhD (Chem), engineer of chair of macromolecules compounds and colloid chemistry of Voronezh State University, Voronezh 